\title{
$\begin{array}{ll}\text { Research Square } & \begin{array}{l}\text { Preprints are preliminary reports that have not undergone peer review. } \\ \text { They should not be considered conclusive, used to inform clinical practice, } \\ \text { or referenced by the media as validated information. }\end{array}\end{array}$
}

\section{Physiological stress response of the Wistar albino rats orally exposed to polystyrene nanoparticles}

\author{
Ali Akbar Babaei \\ Ahvaz Jondishapour University of Medical Sciences \\ Mohammad Rafiee \\ Shaheed Beheshti University of Medical Sciences \\ Fariba Khodagholi \\ Shaheed Beheshti University of Medical Sciences \\ Elham Ahmadpour \\ Ahvaz Jondishapour University of Medical Sciences \\ Fatemeh Amereh ( $\nabla$ amereh@sbmu.ac.ir) \\ Shaheed Beheshti University of Medical Sciences https://orcid.org/0000-0003-3073-0314
}

Research

Keywords: Polystyrene nanoplastics, Rat, Accumulation, Biomarker, Oxidative stress

Posted Date: April 30th, 2020

DOI: https://doi.org/10.21203/rs.3.rs-23042/v1

License: (c) (i) This work is licensed under a Creative Commons Attribution 4.0 International License. Read Full License 


\section{Abstract}

Background Few studies have examined nano-sized plastic particulates (NPs) exposure in relation to oxidative stress and biochemical responses in rodents, commonly used for toxicity evaluations on which to base risk assessment for humans.

Methods Here we explored possible oxidative stress and biochemical responses of five weeks oral exposure to polystyrene (PS) nanoparticles (1, 3,6 and $10 \mathrm{mg} / \mathrm{kg}$ body weight per day) in male rats. We used variance analysis and variance explained statistic eta-squared ( $\left.\eta^{2}\right)$ to estimate the strength of relationships worked out. The whole body scanning further provided insight into the bio-distribution of nanoplastics upon oral exposure.

Results Results demonstrated the accumulation of PS-NPs through whole body and also a dose-dependent increase in the production of reactive oxygen species (ROS). Significant alterations in antioxidant responses including serum levels of catalase, superoxide dismutase (SOD), and total glutathione content were noticed, pointing towards a perturbation of redox state induced by the exposure conditions. Acetylcholinesterase level in highest dose group was about 40 percent lower than those in control group. Biochemical parameters viz. glucose, cortisol, lipase, lactate, lactate dehydrogenase (LDH), alkaline phosphatase, gamma-glutamyl transpeptidase (GGT), triglycerides, and urea showed a significant increase, while total protein, albumin and globulin levels showed an appreciable decline.

Conclusion The pattern of associations noticed with AChE activity and biochemical responses in our study suggests the possibility that a neurobehavioral effect or dysfunctions in energy metabolism, or both, may be the potential mode of action, possibly through stress response as well as liver function. Perturbations of creatinine and uric acid levels are indeed plausible biological explanations for the association with kidney dysfunction. Although we provided a new scientific clue for exploring the biological effects of plastics nanoparticles, the results warrant additional research with a larger sample size. The suggested potential mechanisms also remains to be investigated.

\section{Background}

Reports of plastic pollution have mounted serious environmental concerns for the potential adverse influences on marine, wildlife and public health. Even with concerted global effort, the amount of particulate plastics - small plastic fragments or beads (i.e., $5 \mathrm{~mm}$ down to the nanometer range) - in the environment are continuing to grow [1, 2]. The second United Nations conference on the environment, held in Rio de Janeiro, Brazil 2015, listed the pollution of microplastics as the second most considerable scientific issue in the field of environment and ecology [3]. Although plastic particles have been highlighted to induce various physiological disorders, the cellular and molecular mechanisms linking exposure to microscopic plastic particulates and potential health hazards remains to be elucidated. Nonetheless, oxidative stress, genotoxicity, neurotoxicity, inflammation as well as dysregulation of lipid and energy metabolism have been the proposed mechanisms, among others, reported in the literature $[4,5,6]$. The principles of plastic particulates toxicity have been extensively reviewed $[7,8,9,10,11]$, even though evidences of harmful effects have mostly restricted to observation on marine and aquatic species and albeit microplastics. Public health and environmental concerns, however, increasingly drive efforts to unravel the potential effects following exposure to nanoplastics (NPs - fragments $\leq 100 \mathrm{~nm}$ ) in humans which could be a future prime concern. Compared with MPs, nano-sized plastic particulates are of particular concern, accounting for their plausible interaction with living organisms as they are more likely to cross biological barriers, accumulate in organs and affect the function of cells causing systemic exposure [12, 13]. This becomes even more complicated as the contamination of nano(micro)- plastics on terrestrial environment has been argued to be 4 to 23 -fold greater than in the marine [14], and more remarkably, mammals at high trophic level are regularly in the throes of exposure to nano(micro-) plastics through drinking water, inhalation and food chain all over the world $[15,16,17]$.

Oxidative stress reflects a disturbed balance between the systemic generation of potentially damaging reactive oxygen and nitrogen species (ROS and RNS, respectively) and an organism capacity to readily detoxify the reactive intermediates through antioxidant defenses or to repair the resulting damage. ROS has become an area of great concern for scientists due to the fact that this pathway of programmed health deterioration has also resulted in poor fertilization, poor embryonic development, pregnancy loss, birth defects (including autism), and childhood cancer [18].

There are innate antioxidant defenses to cope with the threat in the body. Rampaging free radicals are neutralized by the action of a battery of enzymatic (e.g. superoxide dismutase, catalase (CAT), glutathione peroxidase, glutathione S-transferase, and glutathione reductase (GR), among others) and non-enzymatic (e.g. glutathione, ubiquinol, uric acid) components during normal metabolism in the body where delay or inhibit cellular damage through their free radical scavenging property $[19,20,21]$. Acetylcholine (Ach) - cholinergic system's neurotransmitter - on the other hand, takes a leadership role in nervous system and assessing the effects of environmental insults [22].

On the premise of this point of view, and considering an unappreciated set of responses at molecular signaling and stress response pathways in an in vivo model, we suggest them as early warning signals for predicting adverse effects at higher biological organization levels (population or community) following the relatively long-term (35 days) exposure with polystyrene NPs (PS NPs). This response was assessed based on the measurements of oxidative stress biomarkers through either free radical production or key antioxidant enzymes activities, as well as some biochemical parameters related to the liver and kidney function. The release of lactate dehydrogenase (LDH) was also worked out to figure the integrity of cells induced by PS NPs. Adult male Wistar rats were used as a model species to investigate the implications on human health and body, because they are known as the chief model in numerous fields, such as neurobehavioral and toxicological studies [23]. This paper is one of a series of papers [24, 25, 26] describing a comprehensive study on the potential mechanisms of toxicity and hence therein possible effects of nano(micro)plastics uptake on human health. The results obtained provide detailed information on the potential health risks of microscopic plastic particulates exposure to mammals including human. 


\section{ROS, enzymatic activities of CAT and SOD and GSH content}

Following exposure to PS-NPs, there observed a tangible dose dependent increase in ROS levels in exposed rats. There was a clear trend of separation between the control and PS-NPs exposure groups with $166.82 \%$ increase $\left(p=0.001, \eta^{2}=0.72\right)$ in ROS activity in the fourth group exposed to $10 \mathrm{mg} / \mathrm{kg}$ day (Fig. 2). Exposure to smaller dosages caused an increase of ROS, however, the observed perturbations were not appreciable ( $p<0.05)$. Chemically reactive compounds containing oxygen, including peroxides, superoxide, and hydroxyl radicals as well as singlet oxygen represent ROS [27].

To obtain a broader picture, the treatment effects of PS-NPs are compared with a series of enzymes activities to quantify the level of oxidative stress (Fig. 3). The effect of PS nanoparticles on catalase activity is presented in Fig. 3a. Catalase activity was increased slightly following exposure experiments. This finding can be inferred that the increase in CAT activity was possibly related to the defense mechanism against nanoparticles exposure. It is, however, supported by the increase in the ROS content as observed in Fig. 2.

In the present study, perturbations in SOD activity noticed following exposure to PS-NPs did not reach statistical significance $(p=0.4)$ (Fig. $3 b)$. In view of the ES $\left(\eta^{2}=0.21\right)$, which estimates the clinically important differences between groups, the activity of CAT and SOD ranged from 0.26 to $0.88 \mu \mathrm{mol} / \mathrm{ml}$ and 91 to $114 \mathrm{U} / \mathrm{ml}$, respectively. ROS accumulation is prevented by GSH, the reduced form of glutathione, that contributes in the detoxification of lipid peroxide and $\mathrm{H}_{2} \mathrm{O}_{2}$ peroxides into less-toxic hydroxyl compounds. GSH can be inactivated by the sizeable ROS production, resulting in the overwhelming antioxidant defense system. As shown in Fig. 4, the content of GSH declined markedly following exposure to PS-NPs ( $p$ $=0.05, \eta^{2}=0.35$ ). If the observed positive associations between exposure to PS-NPs and ROS production and a concurrent significant decline in GSH content in the present study are causal, they could be explained by increased glutathione peroxidase (GPX) activity.

\section{Acetylcholinesterase activity}

It was ever reported that microplastics could pose neurotoxicity through the inhibition of AChE activity [28, 29, 30]. Some studies have also addressed the relationship between toxicity mechanisms and neurobehavioral alterations in mice exposed to pristine polystyrene microplastics [29] [11]. PS-NPs in our study resulted in AChE inhibition in a dose dependent manner, suggesting a neurotoxic effect of nanoplastic particulates, while the lowest dose (1 mg/kg-day) demonstrated a non-significant partial effect (Fig. 5).

\section{Biochemical responses}

As shown in Fig. 6, the heatmap showed that there were differences in the level of some biochemical parameters among different groups. The levels of biochemical parameters in the serum samples from different treatments are shown in Table 1. As can be seen, exposure to PS-NPs caused significant alterations in biochemical parameters associated with energy metabolism and stress response (glucose and cortisol) as well as liver function (GGT and ALP). Kidney disorders were also confirmed by the perturbation of creatinine and uric acid levels, as compared to the control group in a dose dependent manner. We attempted to establish a link between the biochemical alternations and the stress in exposed rats. Glucose and cortisol revealed statistically significant increment following exposure experiments, suggesting that these animals are stressed. Cortisol plays a major role in the stress response and widely used as a reliable biomarker in toxicology. This hormone is secreted from the teleost head kidney through the hypothalamo-pituitary-interrenal (HPI) axis [31] to increase the energy availability during prolonged stress. This task is accomplished primarily through gluconeogenesis, resulting in higher levels of plasma glucose [32,33]. The disruption of energy metabolism was indeed verified by the alteration of lactate where it's levels showed significant $\left(p<0.001, \eta^{2}=0.73\right)$ increment with large effect size following exposure to PS-NPs [34]. Lactate is a normal product of anaerobic metabolism in the body, where pyruvate - the glycolysis product - is metabolized by LDH into lactate.

Table 1

Turkey's multiple comparison of serum biomarkers. Rats orally administered with PS NPs compared to the control group (6 animals in each group). Results are expressed as means. (GGT : gamma-glutamyl transpeptidase, ALP : alkaline phosphatase)*

\begin{tabular}{|c|c|c|c|c|c|c|c|c|c|c|c|}
\hline & $\begin{array}{l}\text { Total } \\
\text { protein }\end{array}$ & Albumin & Globulin & Lactate & Lipase & GGT & $\begin{array}{l}\text { lactate } \\
\text { dehydrogenase }\end{array}$ & ALP & Triglyceride & Urea & Glucose \\
\hline PS NPS & $(\mathrm{g} / \mathrm{dl})$ & $(g / d l)$ & $(g / d l)$ & $(\mathrm{u} / \mathrm{l})$ & $(\mathrm{u} / \mathrm{l})$ & $(\mathrm{u} / \mathrm{l})$ & $(\mathrm{u} / \mathrm{l})$ & $(\mathrm{u} / \mathrm{l})$ & $(\mathrm{mg} / \mathrm{dl})$ & $(\mathrm{mg} / \mathrm{dl})$ & $(\mathrm{mg} / \mathrm{dl})$ \\
\hline $\begin{array}{l}\text { Dose } \\
\text { (mg/kg/day) }\end{array}$ & & & & & & & & & & & \\
\hline 0 & $7^{a}$ & $3.18^{a}$ & $3.82^{\mathrm{a}}$ & $5.5^{\mathrm{a}}$ & $6.5^{\mathrm{a}}$ & $8.5^{\mathrm{a}}$ & $150^{\mathrm{a}}$ & $415.75^{a}$ & $88.25^{\mathrm{a}}$ & $38^{a}$ & $99.5^{a}$ \\
\hline 1 & $6.9^{a}$ & $3.05^{\mathrm{ab}}$ & $3.84^{a}$ & $6.5^{\mathrm{a}}$ & $12^{\mathrm{ab}}$ & $10.75^{a}$ & $156^{a}$ & $455.25^{\mathrm{ab}}$ & $89.35^{a}$ & $38.5^{a}$ & $153.5^{b}$ \\
\hline 3 & $5.13^{b c}$ & $2.89^{b c}$ & $2.22^{b}$ & $10.75^{a b}$ & $13^{\mathrm{bc}}$ & $14.75^{\mathrm{a}}$ & $167.75^{a}$ & $484.25^{\mathrm{ab}}$ & $98^{a b}$ & $44.75^{\mathrm{b}}$ & $155.5^{\mathrm{b}}$ \\
\hline 6 & $4.95^{\mathrm{b}}$ & $2.94^{\mathrm{abc}}$ & $2^{b}$ & $12.25^{\mathrm{b}}$ & $19^{\mathrm{cd}}$ & $15.25^{a}$ & $165.25^{\mathrm{a}}$ & $492.5^{a b}$ & $106.13^{b}$ & $51.75^{c}$ & $157.75^{b}$ \\
\hline 10 & $5.78^{c}$ & $2.8^{\mathrm{c}}$ & $2.97^{c}$ & $15.25^{\mathrm{b}}$ & $21.75^{d}$ & $25.75^{b}$ & $205^{b}$ & $510.25^{d}$ & $123^{c}$ & $55.13^{c}$ & $162.75^{b}$ \\
\hline
\end{tabular}


In the present study, a significant and meaningful increment in LDH activity was noticed in exposed rats as compared to the control group ( $p=0.001$, $\eta^{2}=0.7$ ), which could be attributed to necrosis of hepatocytes, heart failures, kidney dysfunction, renal cells necrosis, muscular dystrophy, anemia, and an increased glycolytic capacity [35].

Lipase, secreted from pancreas, performs essential roles in digestion, transport and processing of dietary lipids (e.g. triglycerides, fats, oils) in most living organisms [36]. Statistically and clinically significant correlations observed between nanopolystyrene particles exposure particularly at mid and highest dosages (3, 6 and $10 \mathrm{mg} / \mathrm{kg}$-day) and lipase levels suggest that the pathways involved in cholesterol and triglycerides metabolism are correlated and that the damage to the pancreas cells could also impair serum levels of lipase in the body.

Creatinine and uric acid are very sensitive biomarkers of kidney dysfunction serving as early warning signals for predicting adverse outcomes [37]. The levels of these parameters quantified in the serum of rats were significantly higher with PS-NPs exposure at dosages of 3, 6 and $10 \mathrm{mg} / \mathrm{kg}$-day; however, their levels were significantly increased among those with highest exposure dosage.

At exposure dosages lower than $6 \mathrm{mg} / \mathrm{kg}$-day, ALP activity increased slightly. However, PS-NPs at $10 \mathrm{mg} / \mathrm{kg}$-day remarkably increased the ALP activity. An ANOVA and Tukey's multiple comparison analyses revealed that there were no appreciable differences in ALP activity among rats treated with PSNPs at dosages $\leq 6 \mathrm{mg} / \mathrm{kg}$-day; however, the activity was significantly increased by $10 \mathrm{mg} / \mathrm{kg}$-day (Table 1). Moreover, based on large effect size and confidence interval, the effect of NPs on ALP activity is considerable and conclusive $\left(\eta^{2}=0.49\right)$.

GGT activity reveals the same pattern, demonstrating a statistically and clinically significant increase in the highest exposure dosage as compared with the control and other treatment groups $\left(p<0.001, \eta^{2}=0.74\right)$. The augmented activity of GGT is explained by GGT sensitivity to environmental insults [38]. The 35 days exposure of rats to PS nanoplastics resulted in remarkable and nonignoable dose-dependent decrease in the serum total protein, albumin, and globulin levels, while the ratio of albumin/globulin significantly increased at 3 and $6 \mathrm{mg} / \mathrm{kg}$-day exposed groups. The obvious reduction in serum total protein, albumin, and globulin levels could endanger efficient absorption of amino acids in the intestine. The observed alterations might also be caused by impairments in protein digestion and absorption process and declined protein synthesis in the liver.

\section{Discussion}

Blood biochemistry deals with the processes that occur within living cells and between cells which in turn relates greatly to the prediction of tissues, organs, and organism structure and function [39]. Oxidative stress and biochemical processes are closely related to several abiotic and biotic factors; among them, environmental insults are considered key players [40]. The literature already includes several reports of adverse effects of different pollutants on metabolic profiles of aquatic and terrestrial organisms; however, the effects of nano-scale plastics have been poorly elucidated [11, 40 , 41,42 ]. Even though microplastics (either virgin or with sorbed chemical pollutants) are known to induce various apical endpoints, toxicological investigations rarely use cellular biomarkers to test metabolic defects of nano-sized plastics, particularly in rodent species usually used for toxicity studies on which to base risk assessment for humans. The present study reports the first appraisal of toxicity and related biomarker responses induced by nano-scale plastics in rats and provides new insights into the possible mechanism for toxicity of nano-sized plastic particulates in humans.

Several macromolecules in the body including proteins, DNA and lipids are susceptible to the oxidative damage caused by these constituents [43]. The literature already includes several reports of ROS generation and the subsequent toxic effects such as genetic, mitochondrial and DNA damages in toxicity studies with engineered metal (oxide) nanoparticles [44, 45]. A number of studies have also, in agreement with our findings, reported the induction of oxidative stress caused by exposure to small pieces of plastics [46].

CAT plays a fundamental role in decomposition and reduction of $\mathrm{H}_{2} \mathrm{O}_{2}$ to water and oxygen by using either iron or manganese as a cofactor. CAT is responsible to directly scavenge reactive oxygen species. Although the difference was marginally significant $(p=0.07)$, it was possible to draw a meaningful conclusion relating to the impact of nanoplastics exposure on CAT activity pointing toward the large effect size $\left(\eta^{2}=0.72\right)$ obtained. However, with a small sample size, caution must be applied as the results of CAT analysis are unreliable based on the confidence interval results, demonstrating that the study needs to be replicated with a larger sample size or meta-analysis.

The literature is somewhat contradictory with respect to the induction of oxidative stress and the antioxidant defense during exposure to microscopic plastic particles. Some studies have reported altered oxidative stress biomarkers concentrations, for example, increased activity of CAT following microplastics exposure in clam Scrobicularia plana [47], scleractinian coral Pocillopora damicornis [48] and African catfish (Clarias gariepinus) [49]. This same general trend was reported by Revel et al., 2019 [50], who pointed out an appreciable increase in CAT activity in Blue Mussel Mytilus spp. exposed to a mixture of microplastics, but a lack of changes in ROS production. They explained this result by the sensitivity of exploited technique (flow cytometery) and/or the sampling time chosen for its measurement. However, polystyrene microplastics in juvenile Eriocheir sinensis and larval zebrafish significantly alleviated the activity of CAT [51, 52]. In contrast, in a study involving Mytilus galloprovincialis, Sendra [53] reported a decreased percentage of ROS as a result of exposure to different sizes of PS-NPs.

SOD, the pioneering detoxifying enzyme, catalyzes the breakdown of ROS-generating superoxide anion (O2-) and is a key component within the primary defense system against oxidative stress-induced damage. 
Lactate is cleared from the blood, primarily by the liver and, to a lesser extent, by the kidneys and skeletal muscles. Hyperlactatemia and lactic acidosis, a serious and sometimes life-threatening condition, is reflected by imbalance between the systemic generation of lactate and its clearance, or a combination of both. However, all of the available literature have found that the lipase or lactate levels in living organisms did not significantly change when exposed to micro/nano plastics [54,55]. Although, ecotoxicological data on blood levels of lactate under nano(micro)plastics exposure are scarce, Karami et al. [54], have reported no negative impact of pristine or phenanthrene-loaded polyethylene fragments on African catfish.

The analysis of LDH provides a clearer picture whether - and to what extent - the energy metabolism was disrupted following exposure experiments. LDH activity has been widely accepted as a good biomarker of alterations in energy pathways induced by xenobiotics [56].

The observed positive associations between PS nanoplastics and a concurrent dose-dependent increase in creatinine and uric acid levels could be explained by dose-response kidney deterioration. Some studies in rats have reported increased creatinine concentrations as a consequence of kidney damage compared with control subjects [57]. It is somewhat surprising that translocation of fluorescent polystyrene nanoparticles from gastrointestinal tract to kidney has been previously reported in rats [58], and also possibly in our work. Increased levels of creatinine have also been reported in common carp (Cyprinus carpio) exposed to sub-lethal concentrations of microplastic and/or paraquat [34]. The increase in serum levels of urea provides further evidence for the toxicity of PS-NPs to the liver, as urea is the end-product of protein catabolism, which is in good agreement with proteins concentrations. Wright and Kelly [59] also revealed that MPs can accumulate and exert dose-dependent localized-particle toxicity by inducing inflammation and immune mechanisms in human.

As a cellular membrane enzyme, ALP catalyzes the dephosphorization of nucleotides, proteins, and alkaloids at an alkaline $\mathrm{pH}$ [54]. This enzyme may be liberated into the plasma because of the degeneration and necrosis of hepatocytes following exposure to NPs [60]. The increased activity of ALP in exposed animals may be speculated by damage to the membrane of liver cells, bile ducts, intestine mucous lining, and the renal tract [54].

The impact of microplastics at high dosages on common carp (Cyprinus carpio) (at $2 \mathrm{mg} \mathrm{L}^{-1}$ ) [34] and amazonian cichlid (at 200 $\mu \mathrm{g} \mathrm{L}{ }^{-1}$ ) [55], on ALP activity has been studied, demonstrating decreased ALP activity; but the impact of nano-scale plastic particulates exposure particularly on mammalians is still unknown. Karami et al., [54] also reported no magnification or diminution in plasma ALP activity of African catfish (Clarias gariepinus) because of exposure to LDPE MPS. By and large, these studies reflected some dearth in the digestive capabilities of exposed animals.

GGT is usually the first hepatic enzyme to rise in the blood as a consequence of bile ducts obstruction, which take bile from the liver to the intestines. Accordingly, it is the most sensitive bio indicator $\mathrm{n}$ the body for detecting bile duct troubles. Nevertheless, the GGT analysis is not specific candidate for differentiating between various causes of liver damage, as it may be increased by many types of liver diseases [54, 61], which is in line with visible accumulation of labeled PS NPs in the liver (Fig. 7). However, GGT coupled with other tests provides a lot of useful advice in determining the plausible cause of elevated ALP levels. To test whether the increment in ALP is corresponded to bone tissue damage, we assessed the serum levels of GGT. As both GGT and ALP levels shows increasing trends by exposure dosage, we speculate that the liver is damaged. If only ALP had increased, it would have indicated bone tissue damages. Therefore, GGT was used as a follow up to an elevated ALP to help in determining the damaged liver or tissue the bile ducts. This was in line with ROS (Fig. 2), where an increase in nanoplolystyrene doses is associated with oxidative stress that is a strong inducer of ALP in various tissues [62]. Perturbations in plasma GGT activity was also observed in common carp (Cyprinus carpio) where its activity decreased when exposed to micro-plastic particles [34].

Albumin and globulin decrement may also be assigned to the reduced protein synthesis in the liver of NPs-exposed animals. Decreased albumin levels may indeed result in osmoregulation defaults in blood [54]. The observed dose-dependent decreasing pattern in globulin levels could be attributed to the reduced immunity in exposed animals $[63,64]$. The high ratio of $A / G$ points towards the plausible liver and kidney tissues deterioration, which is in good agreement with the results of poor liver function. In line with our findings, exposure to MPs had induced alterations in the levels of total protein, globulin, and A/G ratio of African catfish (C. gariepinus), common carp (Cyprinus carpio), Nile Tilapia (Oreochromis niloticus) and gilthead seabream (Sparus aurata L.) $[34,54,65]$.

The large effect size with meaningful changes put forward the generation of $\mathrm{O}_{2}{ }^{-}$may act a prime cause of oxidative impairment. Since $\mu_{0}$ is inside the interval, it was not possible to draw a meaningful conclusion relating to the increased activity of SOD in the present study and thus this result should be again repeated with higher sample size or meta-analysis should be done. However, the plausible inflammation and destabilization of lysosomal membranes could also be occurred [47]. To our knowledge, to date only one study has pointed out the toxic effects of nano(micro)plastics on SOD activity in rodent species [29]. Compared to the negative control and tris (2-chloroethy) phosphate (TCEP) alone, the binary mixture of PS-MPs and TCEP in that study induced the lowest activity in mice (Mus musculus). Rodent studies, however, have demonstrated alterations in SOD activity due to engineered nanoparticles exposure early in life or in adulthood $[40,66,67]$. Likewise, in the intestine of male marine medaka (Oryzias melastigma), chronic exposure to PS particles $(10 \mu \mathrm{m})$ led to increased activity of SOD, while in females its activity was significantly decreased in ovaries [68]. Additionally, PS microbeads caused remarkable increase of SOD activity in zebrafish Danio rerio [5]. In this context, Ribeiro et al. [47] worked on the effects of clam Scrobicularia plana exposure to PS-MPs on oxidative stress biomarkers. From the battery of biomarkers (SOD, CAT, GST and GSH), only SOD was marked as the most prominent, other parameters did not show clear patterns of change. Given the conflicting data reported, clarity on the perturbations in SOD activity from exposure to nano(micro)plastics awaits outcome of further studies.

It has been proved that GPX detoxifies hydrogen peroxide or organic hydroxy peroxides through consumption of GSH. Meanwhile, GSH is used as a cofactor or substrate for GST (glutathione-S-transferase) [69]. Alternatively, associations might be explained by a combination of oxidative stress and

Page 5/15 
enzymatic activities of antioxidant defense. The literature on associations between exposure to nano(micro)plastics and GSH content in aquatic organisms is not conclusive. According to Jeong et al., 2016 [70], for example, a toxicity study of fluorescently labeled polystyrene microbeads with different sizes $(0.05,0.5$, and $6 \mu \mathrm{m})$ on Monogonont Rotifer (Brachionus koreanus) showed increased GSH content after $12 \mathrm{~h}$ in a size-dependent manner. Contrary to this study, however, declined GSH content has been reported in larval zebrafish [51, 71] and juvenile Eriocheir sinensis [52] exposed to MPs. Overall, there are diverging results concerning GSH content and evidence on the relationship between GSH content and oxidative stress are not sufficient.

Acetylcholinesterase, also known as acetylhydrolase, is the primary cholinesterase in the body, catalyzing the breakdown of acetylcholine and of some other choline esters that function as neurotransmitters. An analysis of the data available in the literature already confirms the inhibition of AChE as well as some other cellular antioxidant defense system by ROS [72]. Given the involvement of acetylcholinesterase in neurological functions including some physiological (e.g. growth, reproduction) and behavioural (e.g. memory) processes and irrespective of the mechanism leading to AChE inhibition, the anticholinesterase poisoning of nano-sized PS particulates in rodent species, commonly exploited for toxicity studies on which to base risk assessment for humans, provides an early warning sing of impacts at higher levels (e.g. organism, population). Nonetheless, the first evaluation of polystyrene NPs toxicity on the same subject demonstrated subtle and transient behavioral consequences in adult rats [26], denoting that neurotransmission might not be directly connected to the barely perceptible behavioral disorders. In support of our findings, Wei Lin et al. [73] observed declined AChE activity in Daphnia magna following exposure to various functionalized PS-NPs (PS-p-NH ${ }_{2}, \mathrm{PS}-\mathrm{n}-\mathrm{NH} \mathrm{H}_{2}$ and PS-COOH). They also reported a moderately positive but insignificant association between exposure to pristine plain PS-NPs and AChE activity.

A recent study by Ding et al., [74] tried to assess the AChE activity of red tilapia (Oreochromis niloticus) exposed to $0.1 \mu \mathrm{m}$ PS-MPs. They investigated different concentrations of polystyrene nanoparticles $\left(1,10\right.$ and $\left.100 \mu \mathrm{g} \mathrm{L}^{-1}\right)$ with adult fish for 14 consecutive days. There observed statistically significant reductions in acetylcholinesterase activity in fish brains exposed to PS particulates at all studied concentrations with maximum inhibition rate of $37.7 \%$. Furthermore, although there was significant difference between the control and all exposed groups, no appreciable differences in AChE activity among samples treated with PS-NPs was perceived.

Likewise, in the study of Oliveira et al., [30] the mixture of Red polyethylene microspheres and pyrene induced the highest toxicity in juveniles of Pomatoschistus microps in terms of AChE activity inhibition, compared to MPs alone.

Cell membranes damage will indeed wield causal elevated levels of LDH in the blood [39]. In mice treated by polystyrene microplastics, Deng et al. [29] also observed an increasing trend in liver LDH activity with MPs exposure $(p<0.05)$. Likewise, in Amazonian cichlid, significantly higher LDH concentrations were observed after polystyrene MPs exposure [55]. In contrast, Karami et al. [54] found no association between activation of this enzyme and virgin microplastics exposure in African catfish. In a study on common carp (C. carpio) with and without exposure to microplastic particles, Haghi and Banaee [34] did not notice a meaningful LDH activity. Similar results have also been reported in literature, demonstrating depletion in energy production as a consequence of microplastics uptake both in toxicological and ecotoxicological studies [5, 34, 75, 76]. Nevertheless, evidence regarding the effects of plastic particulates exposure and particularly nanoplastics on energy metabolism is not conclusive.

Some studies have reported altered triglycerides concentration in the blood [34, 77], while, a lack of changes in serum levels of triglycerides has also been reported [78]. Triglycerides are needed to maintain the energy balance. In fact, Liver is the pioneering organ regulating the metabolism of triglycerides [79]. Accordingly, the increased circulatory triglyceride levels of exposed animals in our study could be assigned to liver lesions [54, 80] or plausible disturbance in its uptake in the intestinal tract [81]

In order to test whether the observed interruption in energy metabolism with PS-NPs exposure was correlated with oxidative stress, we conducted additional analyses where we noticed ROS content were positively correlated with glucose $(r=0.67, p=0.002)$, triglycerides $(r=0.63, p=0.004)$, lactate $(r=0.71, p=0.001)$ as well as lactate dehydrogenase $(r=0.67, p=0.002)$, demonstrating that elevated levels of these parameters did induce dysfunction and apoptosis in body, possibly through the formation of reactive oxygen species. However, studies underlying the relationship between energy metabolism and oxidative stress following exposure to nano(micro-)plastics is still extremely scarce.

\section{Conclusion}

Dietary exposure to PS-NPs was associated with higher circulating concentrations of ROS and CAT in the present study population of male Wistar rats. The content of GSH also declined markedly following exposure to PS-NPs. Despite the observed subtle effects may be clinically considerable, perturbations in SOD activity following exposure experiments did not reach statistical significance. The concern for nano-scale plastic particulates exposure is generally related to their oxidative stress. However, the pattern of associations noticed with AChE activity and biochemical responses in the present study points towards the possibility that a neurobehavioral effect of nanoplastics or dysfunctions in energy metabolism, or both, may be the potential mode of action, possibly through stress response as well as liver function. Perturbation of creatinine and uric acid levels are also plausible biological explanations for the association with kidney dysfunction. However, with a small sample size, caution must be applied in the judgment of our findings, demonstrating that additional research is needed with a larger sample size.

\section{Methods}




\section{Nanoplastics, chemicals and reagents}

Pristine PS-NPs with nominal diameters of 25 and $50 \mathrm{~nm}$ were delivered by a private plastic company (G. Kisker GbR, Steinfurt, Germany). Binary mixtures of nanoplastics suspensions were freshly prepared every day, just before treatment, by adding predetermined volumes of 25 and 50 nm PS NPs stocks to distilled water ( $\mathrm{pH} 6.9 \pm 0.1$ ) considering equal weights of each chemical. In parallel with toxicological tests, fluorescent PS particles with respective excitation and emission wavelengths of 535 and $550 \mathrm{~nm}$ was used to assess the accumulation and distribution of particulates in the body. PS spheres had $38.92 \mathrm{~nm}$ mean hydrodynamic diameter with negative surface charges $(-9.27 \pm 3.57 \mathrm{mV})$, which were determined through laser diffraction and time-resolved dynamic light scattering (DLS) measurements (Malvern Instruments Ltd, Malvern, UK) (Fig. 1).

All chemicals and reagents including reduced nicotinamide adenine dinucleotide (NADH), nitroblue tetrazolium (NBT), phenazin methosulphate (PMS), ammonium molybdate, hydrogen peroxide (H2O2), 5,5'-dithiobis-(2-nitrobenzoic acid) (DTNB) and acetylthiocholine were purchased from Sigma Chemical (St. Louis, MO, USA). Kit for analyzing ROS was purchased from MyBioSource, USA.

\section{Animals and exposure experiments}

Thirty young sexually mature male rats weighing between $190 \pm 10 \mathrm{~g}$, were kept under standard laboratory conditions (i.e. room temperature $22 \pm 2{ }^{\circ} \mathrm{C}$, 50-60\% relative humidity, $12 \mathrm{~h}$ dark-light cycle with 12-14 air changes per hour). Commercial food and water were available ad libitum. All experimental processes were in strict accordance with the treatment and care of laboratory animals published by the US National Institute of Health guidelines for the care and use of laboratory animals and received approval from the Research, Ethical Committee of the Faculty of Public Health and Safety, Shahid Beheshti University of Medical Science, Iran. After 5 days of acclimatization, rats were randomized into four experimental and control groups, with 6 rats in each treatment group and administrated with 1, 3, 6 and $10 \mathrm{mg}$ NPs/kg body weight per day. The exposure doses used here was based on the Precautionary Principle to reveal the target mechanisms first before evaluating the risk at environmental concentrations. NPs were prepared by treating the stock suspensions in an ultrasonic bath for $15 \mathrm{~min}$ at $42 \mathrm{~W} / \mathrm{L}$ and administered in $500 \mu \mathrm{l}$ Milipore Mili-Q water via oral gavage for 35 consecutive days. The control group received the same volume of distilled water only. At the end of exposure trials, animals were euthanized by chloroform solution. Trunk blood was collected and serum isolated via centrifugation ( $6000 \mathrm{rpm}$ for 5 min at $4{ }^{\circ} \mathrm{C}$ ) in vacutainer tubes, transferred to $1.5 \mathrm{~mL}$ micro centrifuge tubes and stored at $-80^{\circ} \mathrm{C}$ before analysis.

\section{Serum biochemical analysis}

Perturbations in biological responses at the serum level were determined, which encompassed a suite of neurotoxic responses in terms of acetyl cholinesterase activity, oxidative stress-related biomarkers, including ROS profiling and glutathione content, as well as enzymatic activities of antioxidant defense system including superoxide dismutase (SOD) and catalase. Biochemical parameters (total protein (TP), albumin, glucose, lactate, lactate dehydrogenase (LDH), alkaline phosphatase [82], gamma-glutamyl transpeptidase (GGT), lipase, triglycerides and urea) were indeed worked out that could be associated with the exposure to PS NPs.

Acetyl cholinesterase activity was measured by the modified Ellman's colorimetric method [83], assessed by the addition of Ellman's reagent - DTNB using AChEI (acetylcholine) as substrate, for the estimation of respective thiocholine. The absorbance was measured at $405 \mathrm{~nm}$ in ELISA plate reader (Biotek ELx 800, USA), to estimate the amount of ChE liberated by the reaction which is proportional to the AChE activity.

ROS determination was carried out using a 96-well-plate ELISA Kit according to the manufacturer's instructions and detected at 450 nm in ELISA reader. Serum GSH levels were determined using the dithiobis nitrobenzoic acid (DTNB) method - Ellman's method. Accordingly, $60 \mu$ l of sample was used for GSH assay by Ellman's reagent (19.8 mg of DTNB in $100 \mathrm{ml} 0.1 \%$ sodium nitrate and phosphate buffer (pH 7.4)). The absorbance was measured at $412 \mathrm{~nm}$ [84]. The method is based on a colorimetric quantification that can be measured by the formation of GS-TNB complex from DTNB (5-5'-dithiobis [2-nitrobenzoic acid]) in which a yellow color develops because of the DTNB reduction. The glutathione concentration was determined through spectrophotometric method by absorbance at $415 \mathrm{~nm}$.

The assay for superoxide dismutase (SOD) activity involves inhibition of nitro blue tetrazolium reduction. The formation of amino blue tetrazolium formazan is in the nicotinamide adenine dinucleotide, phenazine methosulphate and nitro blue tetrazolium (NADH-PMS-NBT), according to the method of [85], which measured spectrophotometrically at $560 \mathrm{~nm}$. One unit of enzyme activity is defined as that amount of enzyme that results in $50 \%$ inhibition of NBT reduction/ $\mathrm{ml}$ serum.

Catalase activity was determined as previously described [86], based on the formation of a stable complex of hydrogen peroxide with ammonium molybdate. Approximately $20 \mu \mathrm{l}$ of sample was incubated in $1 \mathrm{ml}$ reaction mixture containing $65 \mathrm{mM}$ hydrogen peroxide in $60 \mathrm{mM}$ sodium-potassium phosphate buffer $\left(\mathrm{pH} \mathrm{7.4)}\right.$ at $25^{\circ} \mathrm{C}$ for $4 \mathrm{~min}$. The enzymatic reaction was stopped with $1 \mathrm{ml}$ of $32.4 \mathrm{mM}$ ammonium molybdate and the concentration of developed yellow stable complex of molybdate and hydrogen peroxide was measured at $405 \mathrm{~nm}$.

Colorimetric measurements of the selected biochemical parameters were performed in triplicate on an automatic dry-chemistry analyzer system (TS/technology Alpha - Classic). Globulin concentrations were determined by deducting TP from the albumin concentration.

Cortisol was quantified in the serum through ELISA using commercially available kit (Catalog no. DCM001-12) provided from DiaMetra, Italy, following manufacturer's protocol. 


\section{Tissue accumulation and fluorescence imaging}

Fluorescently labeled PS NPs were dispersed in $500 \mu$ l Milipore Mili-Q water and treated by ultrasonic vibration, the mixed solution was then given once daily (10 mg/kg.d) by oral gavage. The whole body was scanned for fluorescence with a fluorescence imager (KODAK InVivo Imaging System FX Pro, U.S.) at excitation/emission wavelengths of 535/550 $\mathrm{nm}$.

\section{Date analysis and statistics}

All raw data were presented as means and standard error of the means $( \pm$ SEM). The data were initially submitted for normality (Kolmogorov-Smirnov test) and homoscedasticity (Levene's test). Analysis of variance (ANOVA) was employed to assess the significant differences among treatments where was set a priori at the $p \leq 0.05$ for all statistical analyses. The analysis was followed by Tukey's multiple range test to compare individual treatments.

A variance explained statistic eta-squared $\left(\eta^{2}\right)$ was used as the reported effect size, and though ascertaining what constitutes a small/medium/large effect is primarily a function of the context/discipline. For this report $0.01 / 0.059 / 0.138$ was small/medium/large [87]. The strength of relationships between lipids and proteins were assessed using Pearson correlations. Statistical analyses were performed using STATA (version 14.2; StataCorp, College Station, TX, USA).

\section{Declarations}

\section{Acknowledgements}

The authors wish to thank Ahvaz Jundishapur University of Medical Sciences (grant number \# 33011376).

\section{Authors' contributions}

FA and MR participated in study design, in vivo section, experiments, data analysis, and manuscript writing. FK, and AB participated in study design, experiments, data analysis, and manuscript writing. EA participated in parts of experiments, data analysis, and manuscript writing. All authors read and approved the final manuscript.

\section{Funding}

This study was funded by Ahvaz Jundishapur University of Medical Sciences, Ahvaz, Iran (Grant number: 33011376).

\section{Availability of data and materials}

The datasets used and/or analyzed during the current study are available from the corresponding author on reasonable request.

\section{Ethics approval and consent to participate}

All ethical aspects of this study were approved by Ahvaz Jundishapur University of Medical Sciences' Ethics Committee.

\section{Consent for publication}

Not applicable.

\section{Competing interests}

The authors declare that they have no competing interests.

\section{Author details}

${ }^{1}$ Environmental Technologies Research Center, Ahvaz Jundishapur University of Medical Sciences, Ahvaz, Iran. ${ }^{2}$ Department of Environmental Health Engineering, School of Public Health, Ahvaz Jundishapur University of Medical Sciences, Ahvaz, Iran. ${ }^{3}$ Environmental and Occupational Hazards 
Control Research Center, Shahid Beheshti University of Medical Sciences, Tehran, Iran. ${ }^{4}$ Department of Environmental Health Engineering, School of Public Health and Safety, Shahid Beheshti University of Medical Sciences, Tehran, Iran. ${ }^{5}$ Neurobiology Research Center, Shahid Beheshti University of Medical Sciences, Tehran, Iran. ${ }^{6}$ Department of Environment and Occupational Health, Deputy of Health, Ahvaz Jundishapur University of Medical Sciences, Ahvaz, Iran.

\section{References}

1. Frias J, Nash R. Microplastics: finding a consensus on the definition. Marine pollution bulletin. 2019;138:145-7.

2. Rochman CM. Microplastics research-from sink to source. Science. 2018;360 6384:28-9.

3. Rochman CM, Browne MA, Underwood AJ, Van Franeker JA, Thompson RC, Amaral-Zettler LA. The ecological impacts of marine debris: unraveling the demonstrated evidence from what is perceived. Ecology. 2016;97 2:302-12.

4. Brun NR, Koch BE, Varela M, Peijnenburg WJ, Spaink HP, Vijver MG. Nanoparticles induce dermal and intestinal innate immune system responses in zebrafish embryos. Environmental Science: Nano. 2018;5 4:904-16.

5. Lu Y, Zhang Y, Deng Y, Jiang W, Zhao Y, Geng J, et al. Uptake and accumulation of polystyrene microplastics in zebrafish (Danio rerio) and toxic effects in liver. Environmental science \& technology. 2016;50 7:4054-60.

6. Prokić MD, Radovanović TB, Gavrić JP, Faggio C. Ecotoxicological effects of microplastics: Examination of biomarkers, current state and future perspectives. TrAC Trends in Analytical Chemistry. 2019;111:37-46.

7. Kögel T, Bjorøy $\varnothing$, Toto B, Bienfait AM, Sanden M. Micro- and nanoplastic toxicity on aquatic life: Determining factors. Science of the Total Environment. 2020;709; doi: 10.1016/j.scitotenv.2019.136050. https://www.scopus.com/inward/record.uri?eid=2-s2.085077120339\&doi=10.1016\%2fj.scitotenv.2019.136050\&partnerlD=40\&md5=b0fa54ead27cbf2d723103785e61808d.

8. Ma H, Pu S, Liu S, Bai Y, Mandal S, Xing B. Microplastics in aquatic environments: Toxicity to trigger ecological consequences. Environmental Pollution. 2020;261; doi: 10.1016/j.envpol.2020.114089. https://www.scopus.com/inward/record.uri?eid=2-s2.085079187831\&doi=10.1016\%2fj.envpol.2020.114089\&partnerID=40\&md5=85832af42317f7887fbd42c3cd75dd3f

9. Prata JC, da Costa JP, Lopes I, Duarte AC, Rocha-Santos T. Environmental exposure to microplastics: An overview on possible human health effects. Science of the Total Environment. 2020;702; doi: 10.1016/j.scitotenv.2019.134455. https://www.scopus.com/inward/record.uri?eid=2s2.0-85074717728\&doi=10.1016\%2fj.scitotenv.2019.134455\&partnerlD=40\&md5=6e342864b25670e918bfa86655b96321.

10. Wong JKH, Lee KK, Tang KHD, Yap PS. Microplastics in the freshwater and terrestrial environments: Prevalence, fates, impacts and sustainable solutions. Science of the Total Environment. 2020;719; doi: 10.1016/j.scitotenv.2020.137512. https://www.scopus.com/inward/record.uri? eid=2s2.0-85081029089\&doi=10.1016\%2fj.scitotenv.2020.137512\&partnerlD=40\&md5=33b26328e42c388264f4e379e9279907.

11. Yong CQY, Valiyaveetill S, Tang BL. Toxicity of microplastics and nanoplastics in Mammalian systems. International Journal of Environmental Research and Public Health. 2020;17 5; doi: 10.3390/ijerph17051509. https://www.scopus.com/inward/record.uri?eid=2-s2.085080959250\&doi=10.3390\%2fijerph17051509\&partnerID=40\&md5=ed65aeb7b9ac7a056e89697e9dd5d193.

12. da Costa JP, Santos PS, Duarte AC, Rocha-Santos T. (Nano) plastics in the environment-sources, fates and effects. Science of the Total Environment. 2016;566:15-26.

13. Watts AJ, Urbina MA, Goodhead R, Moger J, Lewis C, Galloway TS. Effect of microplastic on the gills of the shore crab Carcinus maenas. Environmental science \& technology. 2016;50 10:5364-9.

14. Horton AA, Walton A, Spurgeon DJ, Lahive E, Svendsen C. Microplastics in freshwater and terrestrial environments: evaluating the current understanding to identify the knowledge gaps and future research priorities. Science of the Total Environment. 2017;586:127-41.

15. Lwanga EH, Gertsen H, Gooren H, Peters P, Salánki T, van der Ploeg M, et al. Incorporation of microplastics from litter into burrows of Lumbricus terrestris. Environmental Pollution. 2017;220:523-31.

16. Rist S, Almroth BC, Hartmann NB, Karlsson TM. A critical perspective on early communications concerning human health aspects of microplastics. Science of the Total Environment. 2018;626:720-6.

17. Van Cauwenberghe L, Janssen CR. Microplastics in bivalves cultured for human consumption. Environmental pollution. 2014;193:65-70.

18. Agarwal A, Virk G, Ong C, Du Plessis SS. Effect of oxidative stress on male reproduction. The world journal of men's health. 2014;32 1:1-17.

19. Deisseroth A, Dounce AL. Catalase: Physical and chemical properties, mechanism of catalysis, and physiological role. Physiological reviews. 1970;50 3:319-75.

20. Halliwell B. Commentary oxidative stress, nutrition and health. Experimental strategies for optimization of nutritional antioxidant intake in humans. Free radical research. 1996;25 1:57-74.

21. Nita M, Grzybowski A. The role of the reactive oxygen species and oxidative stress in the pathomechanism of the age-related ocular diseases and other pathologies of the anterior and posterior eye segments in adults. Oxidative Medicine and Cellular Longevity. 2016;2016.

22. Yen J, Donerly S, Levin ED, Linney EA. Differential acetylcholinesterase inhibition of chlorpyrifos, diazinon and parathion in larval zebrafish. Neurotoxicology and teratology. 2011;33 6:735-41.

Page 9/15 
23. Sengupta P. The laboratory rat: relating its age with human's. International journal of preventive medicine. 2013;4 6:624.

24. Amereh F, Babaei M, Eslami A, Fazelipour S, Rafiee M. The emerging risk of exposure to nano (micro) plastics on endocrine disturbance and reproductive toxicity: From a hypothetical scenario to a global public health challenge. Environmental Pollution. 2020;261:114158.

25. Amereh F, Eslami A, Fazelipour S, Rafiee M, Zibaii MI, Babaei M. Thyroid endocrine status and biochemical stress responses in adult male Wistar rats chronically exposed to pristine polystyrene nanoplastics. Toxicology Research. 2019;8 6:953-63.

26. Rafiee M, Dargahi L, Eslami A, Beirami E, Jahangiri-rad M, Sabour S, et al. Neurobehavioral assessment of rats exposed to pristine polystyrene nanoplastics upon oral exposure. Chemosphere. 2018;193:745-53.

27. Hayyan M, Hashim MA, AINashef IM. Superoxide ion: generation and chemical implications. Chemical reviews. 2016;116 5:3029-85.

28. Barboza LGA, Vethaak AD, Lavorante BR, Lundebye A-K, Guilhermino L. Marine microplastic debris: An emerging issue for food security, food safety and human health. Marine pollution bulletin. 2018;133:336-48.

29. Deng Y, Zhang Y, Lemos B, Ren H. Tissue accumulation of microplastics in mice and biomarker responses suggest widespread health risks of exposure. Scientific reports. 2017;7:46687.

30. Oliveira M, Ribeiro A, Hylland K, Guilhermino L. Single and combined effects of microplastics and pyrene on juveniles (0+ group) of the common goby Pomatoschistus microps (Teleostei, Gobiidae). Ecological Indicators. 2013;34:641-7.

31. Pottinger T. Changes in blood cortisol, glucose and lactate in carp retained in anglers' keepnets. Journal of fish biology. 1998;53 4:728-42.

32. Saravanan M, Kumar KP, Ramesh M. Haematological and biochemical responses of freshwater teleost fish Cyprinus carpio (Actinopterygii: Cypriniformes) during acute and chronic sublethal exposure to lindane. Pesticide Biochemistry and Physiology. 2011;100 3:206-11.

33. Sheridan MA. Alterations in lipid metabolism accompanying smoltification and seawater adaptation of salmonid fish. Aquaculture. 1989;82 14:191-203.

34. Haghi BN, Banaee M. Effects of micro-plastic particles on paraquat toxicity to common carp (Cyprinus carpio): biochemical changes. International journal of environmental science and technology. 2017;14 3:521-30.

35. Chen L, Diao J, Zhang W, Zhang L, Wang Z, Li Y, et al. Effects of beta-cypermethrin and myclobutanil on some enzymes and changes of biomarkers between internal tissues and saliva in reptiles (Eremias argus). Chemosphere. 2019;216:69-74; doi:

10.1016/j.chemosphere.2018.10.099. https://www.scopus.com/inward/record.uri?eid=2-s2.0-

85055965101\&doi=10.1016\%2fj.chemosphere.2018.10.099\&partnerID=40\&md5=4b715286a7f44cfdb67e61c0411d3aec.

36. Winkler F, d'Arcy A, Hunziker W. Structure of human pancreatic lipase. Nature. 1990;343 6260:771-4.

37. Banaee M. Physiological dysfunction in fish after insecticides exposure. Insecticides-Development of safer and more effective technologies: IntechOpen; 2013.

38. Mehrpak M, Banaee M, NEMATDOOST HB, Noori A. Protective Effects of Vitamin C and Chitosan against Cadmium-Induced Oxidative Stress in the Liver of Common Carp (Cyprinuscarpio). 2015.

39. Banaee M, Sureda A, Zohiery F, Hagi BN, Garanzini DS. Alterations in biochemical parameters of the freshwater fish, Alburnus mossulensis, exposed to sub-lethal concentrations of Fenpropathrin. International Journal of Aquatic Biology. 2014;2 2:58-68.

40. Chen Z, Han S, Zheng P, Zhou D, Zhou S, Jia G. Effect of oral exposure to titanium dioxide nanoparticles on lipid metabolism in Sprague-Dawley rats. Nanoscale. 2020.

41. Kim KT, Klaine SJ, Cho J, Kim S-H, Kim SD. Oxidative stress responses of Daphnia magna exposed to TiO2 nanoparticles according to size fraction. Science of the Total Environment. 2010;408 10:2268-72.

42. Kim HM, Lee D-K, Long NP, Kwon SW, Park JH. Uptake of nanopolystyrene particles induces distinct metabolic profiles and toxic effects in Caenorhabditis elegans. Environmental pollution. 2019;246:578-86.

43. Apel K, Hirt H. Reactive oxygen species: metabolism, oxidative stress, and signal transduction. Annu Rev Plant Biol. 2004;55:373-99.

44. Khan MI, Mohammad A, Patil G, Naqvi S, Chauhan L, Ahmad I. Induction of ROS, mitochondrial damage and autophagy in lung epithelial cancer cells by iron oxide nanoparticles. Biomaterials. 2012;33 5:1477-88.

45. Shukla RK, Sharma V, Pandey AK, Singh S, Sultana S, Dhawan A. ROS-mediated genotoxicity induced by titanium dioxide nanoparticles in human epidermal cells. Toxicology in vitro. 2011;25 1:231-41.

46. Hwang J, Choi D, Han S, Choi J, Hong J. An assessment of the toxicity of polypropylene microplastics in human derived cells. Science of The Total Environment. 2019;684:657-69.

47. Ribeiro F, Garcia AR, Pereira BP, Fonseca M, Mestre NC, Fonseca TG, et al. Microplastics effects in Scrobicularia plana. Marine pollution bulletin. 2017;122 1-2:379-91.

48. Tang J, Ni X, Zhou Z, Wang L, Lin S. Acute microplastic exposure raises stress response and suppresses detoxification and immune capacities in the scleractinian coral Pocillopora damicornis. Environmental pollution. 2018;243:66-74.

49. Iheanacho SC, Odo GE. Neurotoxicity, oxidative stress biomarkers and haematological responses in African catfish (Clarias gariepinus) exposed to polyvinyl chloride microparticles. Comparative Biochemistry and Physiology Part - C: Toxicology and Pharmacology. 2020;232; doi:

10.1016/j.cbpc.2020.108741. https://www.scopus.com/inward/record.uri?eid=2-s2.0-

85081960134\&doi=10.1016\%2fj.cbpc.2020.108741\&partnerID=40\&md5=2e3f95672d5343d6863d02112ae79c16.

Page 10/15 
50. Revel M, Chebath J, Izrael M, Kaufman R: Methods of generating glial and neuronal cells and use of same for the treatment of medical conditions of the CNS. Google Patents; 2019.

51. Wan Z, Wang C, Zhou J, Shen M, Wang X, Fu Z, et al. Effects of polystyrene microplastics on the composition of the microbiome and metabolism in larval zebrafish. Chemosphere. 2019;217:646-58.

52. Yu P, Liu Z, Wu D, Chen M, Lv W, Zhao Y. Accumulation of polystyrene microplastics in juvenile Eriocheir sinensis and oxidative stress effects in the liver. Aquatic Toxicology. 2018;200:28-36.

53. Sendra M SA, Yeste MP, Romero A, Novoa B, Figueras A. Nanoplastics: from tissue accumulation to cell translocation into Mytilus galloprovincialis hemocytes. Resilience of immune cells exposed to nanoplastics and a nanoplastic plus Vibriosplendidus combination. Journal of Hazardous Materials. 2019; doi: doi: https://doi.org/10.1016/j.jhazmat.2019.121788.

54. Karami A, Romano N, Galloway T, Hamzah H. Virgin microplastics cause toxicity and modulate the impacts of phenanthrene on biomarker responses in African catfish (Clarias gariepinus). Environmental research. 2016;151:58-70.

55. Wen B, Zhang N, Jin S-R, Chen Z-Z, Gao J-Z, Liu Y, et al. Microplastics have a more profound impact than elevated temperatures on the predatory performance, digestion and energy metabolism of an Amazonian cichlid. Aquatic toxicology. 2018;195:67-76.

56. Al-Attas OS, Hussain T, Ahmed M, Al-daghri N, Mohammed AA, De Rosas E, et al. Ultrastructural changes, increased oxidative stress, inflammation, and altered cardiac hypertrophic gene expressions in heart tissues of rats exposed to incense smoke. Environmental Science and Pollution Research. 2015;22 13:10083-93; doi: 10.1007/s11356-015-4212-5. https://www.scopus.com/inward/record.uri?eid=2-s2.084933179250\&doi=10.1007\%2fs11356-015-4212-5\&partnerID=40\&md5=b8fadec7367ed3639c2501b3009adde6.

57. Rana K, Verma Y, Rani V, Rana SVS. Renal toxicity of nanoparticles of cadmium sulphide in rat. Chemosphere. 2018;193:142-50.

58. Walczak AP, Hendriksen PJ, Woutersen RA, van der Zande M, Undas AK, Helsdingen R, et al. Bioavailability and biodistribution of differently charged polystyrene nanoparticles upon oral exposure in rats. Journal of Nanoparticle Research. 2015;17 5:231.

59. Wright SL, Kelly FJ. Plastic and human health: a micro issue? Environmental science \& technology. 2017;51 12:6634-47.

60. lavicoli I, Leso V, Bergamaschi A. Toxicological effects of titanium dioxide nanoparticles: a review of in vivo studies. Journal of Nanomaterials. 2012;2012.

61. Tang H-Q, Xu M, Rong Q, Jin R-W, Liu Q-J, Li Y-L. The effect of ZnO nanoparticles on liver function in rats. International journal of nanomedicine. 2016;11:4275.

62. Torino C, Mattace-Raso F, van Saase JL, Postorino M, Tripepi GL, Mallamaci F, et al. Oxidative stress as estimated by gamma-glutamyl transferase levels amplifies the alkaline phosphatase-dependent risk for mortality in ESKD patients on dialysis. Oxidative medicine and cellular longevity. $2016 ; 2016$.

63. Ahmad I, Shukla S, Kumar A, Singh BK, Patel DK, Pandey HP, et al. Maneb and paraquat-induced modulation of toxicant responsive genes in the rat liver: comparison with polymorphonuclear leukocytes. Chemico-biological interactions. 2010;188 3:566-79.

64. Egemen D, Şeker D. In-vitro interaction of paraquat with some amino acids. Fen Bilimleri Dergisi. 2003;24 2.

65. Beltrán JMG, Espinosa C, Guardiola FA, Esteban MÁ. Dietary dehydrated lemon peel improves the immune but not the antioxidant status of gilthead seabream (Sparus aurata L.). Fish \& shellfish immunology. 2017;64:426-36.

66. Canli EG, Atli G, Canli M. Response of the antioxidant enzymes of the erythrocyte and alterations in the serum biomarkers in rats following oral administration of nanoparticles. Environmental toxicology and pharmacology. 2017;50:145-50.

67. Abdel-Magied N, Shedid SM. Impact of zinc oxide nanoparticles on thioredoxin-interacting protein and asymmetric dimethylarginine as biochemical indicators of cardiovascular disorders in gamma-irradiated rats. Environmental toxicology. 2019.

68. Wang J, Li Y, Lu L, Zheng M, Zhang X, Tian H, et al. Polystyrene microplastics cause tissue damages, sex-specific reproductive disruption and transgenerational effects in marine medaka (Oryzias melastigma). Environmental Pollution. 2019;254:113024.

69. Barata C, Varo I, Navarro JC, Arun S, Porte C. Antioxidant enzyme activities and lipid peroxidation in the freshwater cladoceran Daphnia magna exposed to redox cycling compounds. Comparative Biochemistry and Physiology Part C: Toxicology \& Pharmacology. 2005;140 2:175-86.

70. Jeong C-B, Won E-J, Kang H-M, Lee M-C, Hwang D-S, Hwang U-K, et al. Microplastic size-dependent toxicity, oxidative stress induction, and p-JNK and p-p38 activation in the monogonont rotifer (Brachionus koreanus). Environmental science \& technology. 2016;50 16:8849-57.

71. Chen Q, Gundlach M, Yang S, Jiang J, Velki M, Yin D, et al. Quantitative investigation of the mechanisms of microplastics and nanoplastics toward zebrafish larvae locomotor activity. Science of the total environment. 2017;584:1022-31.

72. Schülke S, Dreidax D, Malik A, Burmester T, Nevo E, Band M, et al. Living with stress: regulation of antioxidant defense genes in the subterranean, hypoxia-tolerant mole rat, Spalax. Gene. 2012;500 2:199-206.

73. Lin W, Jiang R, Hu S, Xiao X, Wu J, Wei S, et al. Investigating the toxicities of different functionalized polystyrene nanoplastics on Daphnia magna. Ecotoxicology and environmental safety. 2019;180:509-16.

74. Ding J, Zhang S, Razanajatovo RM, Zou H, Zhu W. Accumulation, tissue distribution, and biochemical effects of polystyrene microplastics in the freshwater fish red tilapia (Oreochromis niloticus). Environmental pollution. 2018;238:1-9.

75. Green DS, Boots B, Sigwart J, Jiang S, Rocha C. Effects of conventional and biodegradable microplastics on a marine ecosystem engineer (Arenicola marina) and sediment nutrient cycling. Environmental Pollution. 2016;208:426-34.

Page 11/15 
76. Oliveira P, Barboza LGA, Branco V, Figueiredo N, Carvalho C, Guilhermino L. Effects of microplastics and mercury in the freshwater bivalve Corbicula fluminea (Müller, 1774): Filtration rate, biochemical biomarkers and mercury bioconcentration. Ecotoxicology and environmental safety. 2018;164:155-63.

77. Cedervall T, Hansson L-A, Lard M, Frohm B, Linse S. Food chain transport of nanoparticles affects behaviour and fat metabolism in fish. PloS one. 2012;7 2:e32254.

78. Brandts I, Teles M, Gonçalves A, Barreto A, Franco-Martinez L, Tvarijonaviciute A, et al. Effects of nanoplastics on Mytilus galloprovincialis after individual and combined exposure with carbamazepine. Science of The Total Environment. 2018;643:775-84.

79. Barnhart RA. Effects of certain variables on hematological characteristics of rainbow trout. Transactions of the American Fisheries Society. 1969;98 3:411-8.

80. Begriche K, Massart J, Robin M-A, Borgne-Sanchez A, Fromenty B. Drug-induced toxicity on mitochondria and lipid metabolism: mechanistic diversity and deleterious consequences for the liver. Journal of hepatology. 2011;54 4:773-94.

81. Reis PM, Raab TW, Chuat JY, Leser ME, Miller R, Watzke HJ, et al. Influence of surfactants on lipase fat digestion in a model gastro-intestinal system. Food biophysics. 2008;3 4:370.

82. Sökmen TÖ, Sulukan E, Türkoğlu M, Baran A, Özkaraca M, Ceyhun SB. Polystyrene Nanoplastics (20 nm) are able to bioaccumulate and cause oxidative DNA damages in the brain tissue of zebrafish embryo (Danio rerio). NeuroToxicology. 2019.

83. Ellman GL, Courtney KD, Andres Jr V, Featherstone RM. A new and rapid colorimetric determination of acetylcholinesterase activity. Biochemical pharmacology. 1961;7 2:88-95.

84. Ellman GL. Tissue sulfhydryl groups. Archives of biochemistry and biophysics. 1959;82 1:70-7.

85. Kakkar P, Das B, Viswanathan P. A modified spectrophotometric assay of superoxide dismutase. 1984.

86. Goth L. A simple method for determination of serum catalase activity and revision of reference range. Clinica chimica acta. 1991;196 2-3:143-51.

87. Cohen J: Statistical Power Analysis for the Behavioral Sciences, (L. Erlbaum Associates, Hillsdale, NJ). Erlbaum Associates Hillsdale, NJ.; 1988.

\section{Figures}

A
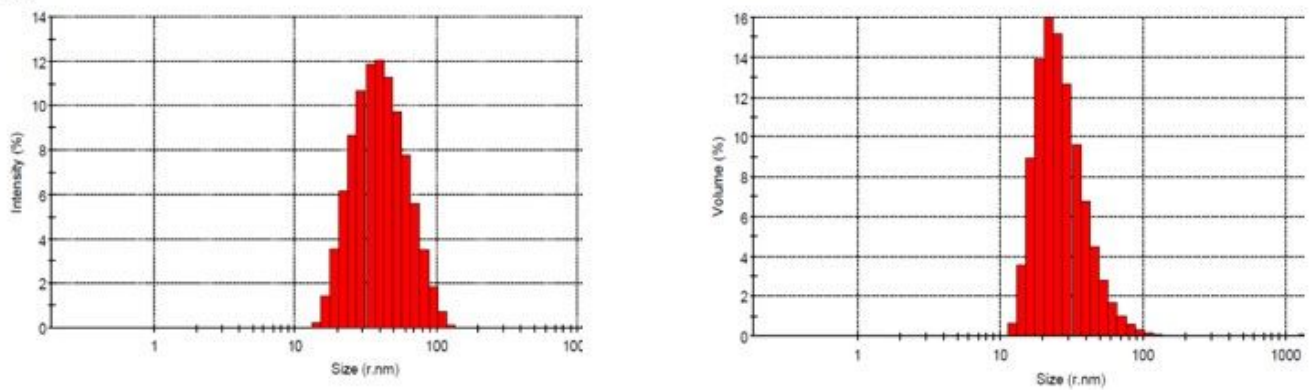

B

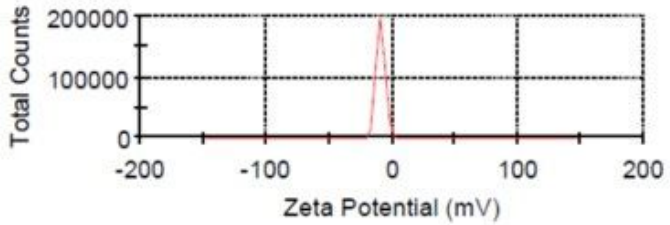

Figure 1

Characterization of PS NPs. (A) The hydrodynamic diameter (B) and zeta potential. 


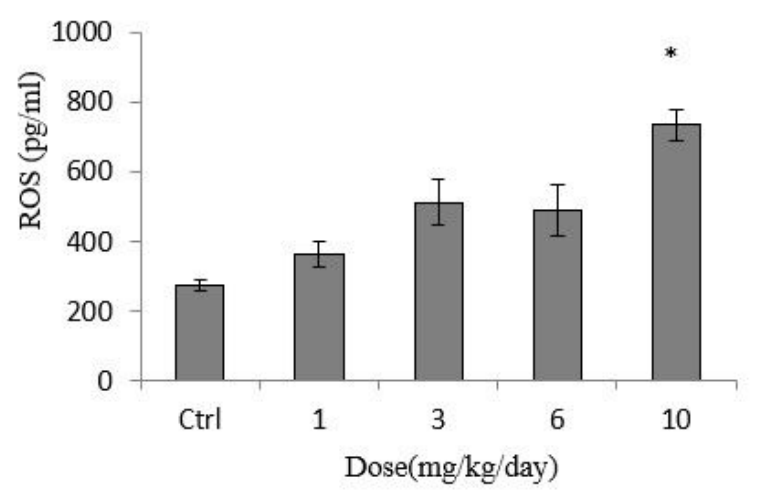

\section{Figure 2}

The levels of ROS in the serum of mature male rats exposed orally to PS-NPs $(0,1,3,6$ and mg/kg b.w.) for $35 \mathrm{~d}$. Data show mean values and associated standard errors mean of 6 rats. Asterisks show significant differences $(p<0.05)$ from control value.
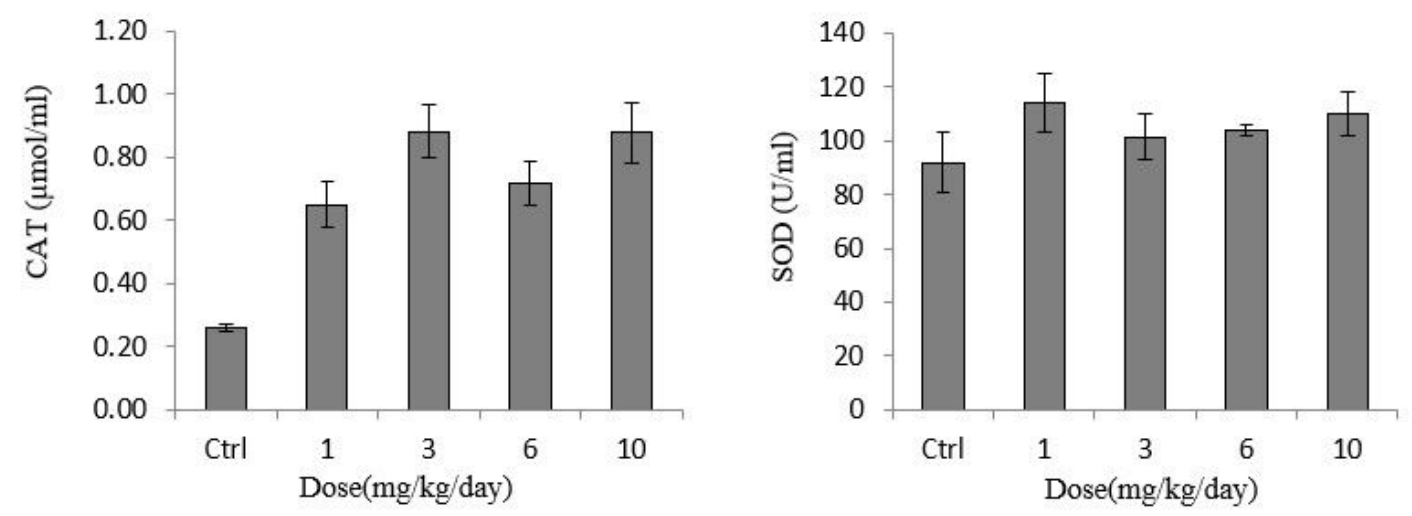

\section{Figure 3}

The activities of CAT and SOD in the serum of mature male rats exposed orally to PS-NPs (0. 1, 3, 6 and 10 mg/kg b.w.) for 35 d. See Fig. 2 . for details. 


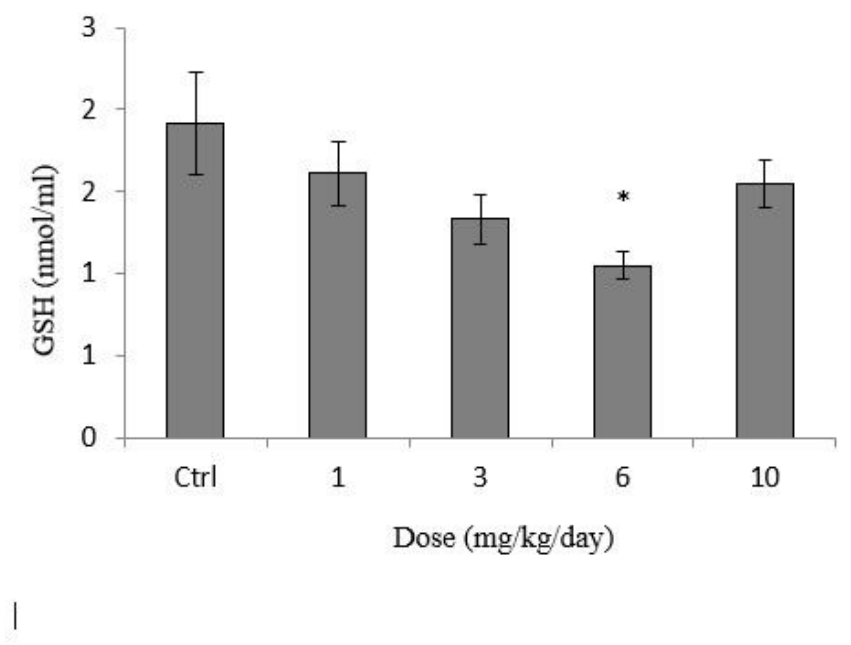

\section{Figure 4}

The levels of GSH in the serum of mature male rats exposed orally to PS-NPs (0, 1, 3, 6 and $10 \mathrm{mg} / \mathrm{kg}$ b.w.) for $35 \mathrm{~d}$. See Fig. 2 . for details.

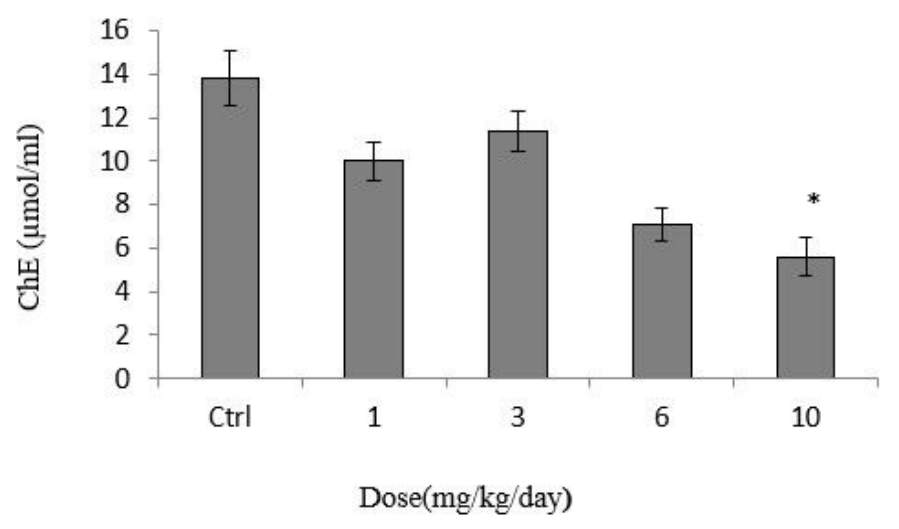

Figure 5

The activities of AChE in the serum of mature male rats exposed orally to PS-NPs (0. 1, 3, 6 and $10 \mathrm{mg} / \mathrm{kg} \mathrm{b.w.)} \mathrm{for} 35 \mathrm{~d}$. See Fig. 2 . for details. 


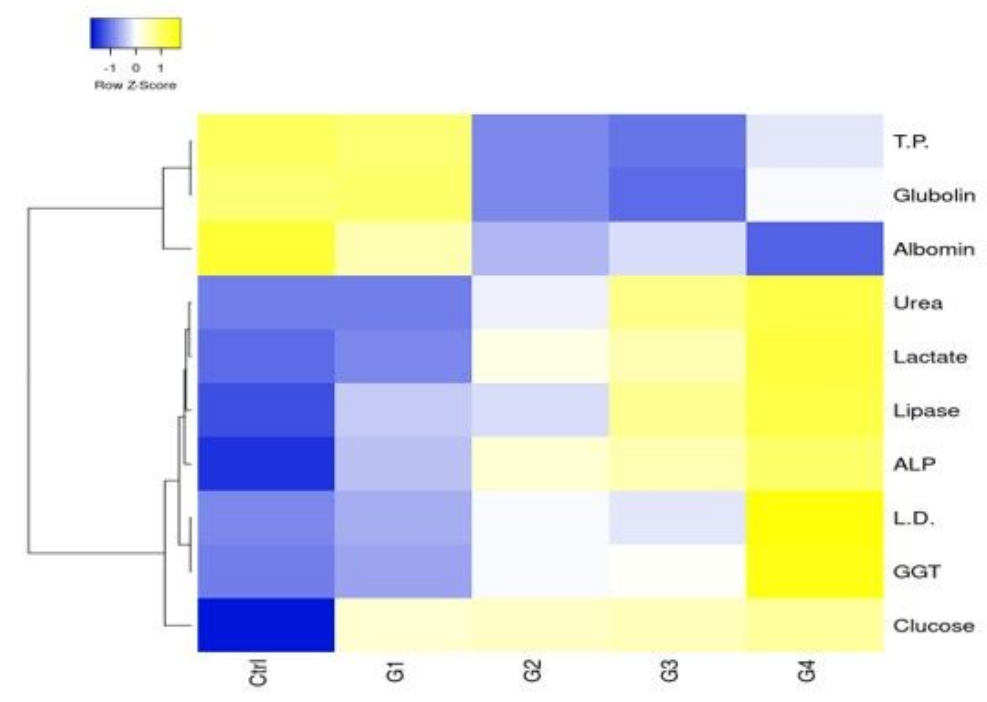

\section{Figure 6}

Heatmap of biochemical parameters, which shows the different parameters in serum of rats. Each row represents a biochemical parameter, and each column represents a group. The color of each grid represents the relative concentration of the biochemical parameters in the corresponding group.

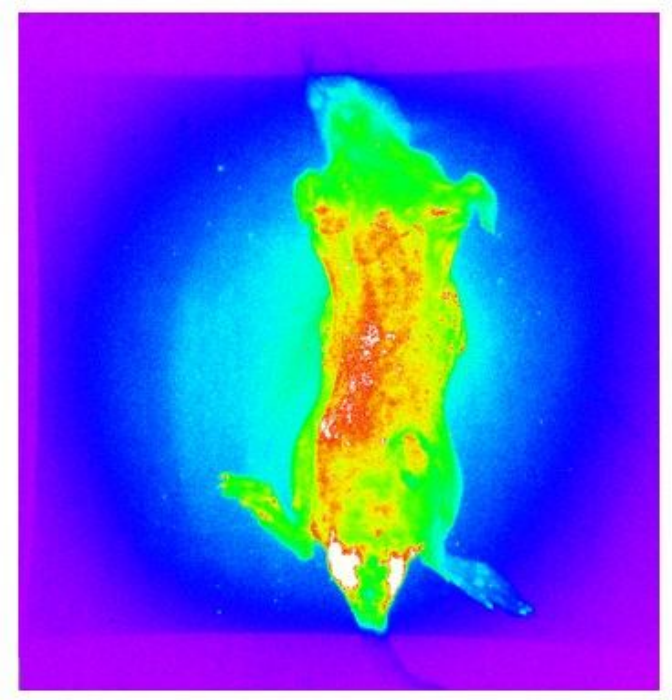

\section{Figure 7}

Image of fluorescently labeled polystyrene microplastic accumulated in liver of rat. 